\title{
Improving the results of pancreatic endoscopic ultra- sound-guided fine needle aspiration in daily practice: keep it simple
}

Authors

Institution ji Young Bang, Shyam Varadarajulu

Center for Interventional Endoscopy, Florida Hospital, Orlando, Florida, United States submitted

23. December 2014

accepted after revision

7. January 2015

\section{Bibliography}

DOI http://dx.doi.org/

$10.1055 / \mathrm{s}-0034-1391416$

Published online: 11.2.2015

Endoscopy International Open

2015; 3: E138-E139

(c) Georg Thieme Verlag KG

Stuttgart - New York

E-ISSN 2196-9736

\section{Corresponding author}

\section{S. Varadarajulu, MD}

Center for Interventional

Endoscopy

Florida Hospital

601 East Rollins Street

Orlando, FL 32803

Fax: +14073032585

svaradarajulu@yahoo.com

\section{License terms}

(ब)(1) $\Theta \circledast$
Endoscopic ultrasound-guided fine needle aspiration (EUS-FNA) is an indispensable tool for tissue acquisition. The National Comprehensive Cancer Network has incorporated EUS-FNA cytology in its diagnostic algorithm for pancreatic cancer [1]. EUS-FNA is a multi-step procedure involving not only best practices in technique but also in specimen collection and processing; thus, rapid on-site evaluation (ROSE), needle selection, and sampling technique determine the outcomes of EUS-FNA diagnosis of pancreatic cancer. The availability of on-site cytopathology services increases diagnostic accuracy and decreases the number of suboptimal specimens such that the non-diagnostic rate has been reported to be as low as $1 \%$ for FNAs with ROSE, whereas it is $20 \%$ without ROSE [2,3]. However, ROSE is not available at many centers because of the time needed, cost, and inadequate financial reimbursement. Hence, most centers depend on off-site laboratory interpretation of FNA specimens.

In this issue of the journal, Schneider and colleagues from Germany report on 63 patients who underwent EUS-FNA of pancreatic lesions in two phases: In phase I, the in-house pathology laboratory evaluated the FNA aspirates, and in phase II, a specialized outside cytology laboratory evaluated them [4]. The diagnostic sensitivity in phase II improved to $91.4 \%$ from $38.5 \%$ found in phase I, which emphasizes the importance of specialized diagnostic services in evaluating FNA specimens. In a retrospective study of 876 EUS-FNA specimens obtained from a tertiary referral center, the overall cumulative sum charts for both the nondiagnostic error rate and diagnostic error rate showed a short learning period and improved to an acceptable level at case numbers 121 and 97, respectively [5]. These findings suggest that like the practice of EUS-FNA where diagnosis improves with the endosonographer's experience [6], the accuracy of specimen interpretation improves with the cytopathologist's experience.
Therefore, high-volume centers practicing EUSFNA must implement ROSE or the services of an off-site cytopathology laboratory to obtain the best diagnostic outcomes.

In addition to specimen interpretation as performed by cytopathologists, the endosonographers must be familiar with the techniques for handling and processing tissues to optimize specimens sent for off-site evaluation. Assigning one person to handle the aspirated materials establishes a protocol for consistent sample preparation and minimizes artifacts resulting from improper tissue handling and collection. Although most endosonographers do not routinely practice in-room cytomorphological analysis, it has been shown that microscopic evaluation of smears by endosonographers without access to ROSE improves diagnostic accuracy [7]. In a recent study, we showed that a short, intensive EUS cytopathology course for endosonographers provided effective training in cytopathological interpretation [8]. In our opinion, consideration must be given to incorporating basic cytopathology during an EUS fellowship to improve the endosonographer's performance of FNA procedures.

There are several technical issues that are critical to improving the results of EUS-FNA of pancreatic lesions. These include needle selection, FNA technique, use of suction or stylet, and the number of passes. Most masses in the pancreas originate in the head region and require transduodenal sampling. This mandates the need for a flexible, thin caliber needle that can easily exit the biopsy channel of the echoendoscope; that is, a needle with an angled tip used during sampling of head and uncinate masses. Limited evidence suggests that a $25 \mathrm{G}$ needle is suitable for sampling pancreatic masses. A recent meta-analysis compared the $22 \mathrm{G}$ and $25 \mathrm{G}$ needles for EUS-FNA of pancreatic masses and found that use of the 25G needle yielded a higher diagnostic sensitivity than the $22 \mathrm{G}$ needle [9]. However, if the endosonographer 
must rely on only the cell block for off-site diagnosis, the $25 \mathrm{G}$ needle may not be optimal. In a recent randomized trial, we demonstrated that the $25 \mathrm{G}$ needle yielded a diagnostic cell block in only $80.5 \%$ of patients irrespective of the number of FNA passes performed [10]. Therefore, in most centers in Europe and Asia, where ROSE is not available, the $22 \mathrm{G}$ needle is used in conjunction with suction for better tissue procurement. There has been growing interest in the use of core biopsy needles for histological tissue procurement when sampling pancreatic masses. However, in a recent meta-analysis, it was evident that the performance of the ProCore biopsy needle was not superior to the performance of the standard FNA needle either for cytological or histological assessment [11].

Although many techniques have been suggested for tissue procurement, our recommendation is to keep the procedure simple! We recommend fanning the needle when sampling a mass. This ensures not only the procurement of good quality tissue that is representative of the lesion (minimizing sampling error) but also allows diagnosis with fewer passes [12]. In addition, we do not recommend the routine use of suction during EUS-FNA because it increases the amount of blood in the specimen. Suction may be used when sampling a mass in the setting of chronic pancreatitis when tissue yield can be minimal, and there is a growing body of evidence that suction may augment the performance of the $25 \mathrm{G}$ needle. In a randomized trial comparing high negative pressure suction ( $50 \mathrm{~mL}$ negative pressure) with normal negative pressure suction ( $10 \mathrm{~mL}$ negative pressure) for EUS-FNA of pancreatic masses using the $25 \mathrm{G}$ needle, a higher proportion of diagnostically adequate samples were obtained using high negative pressure suction $(90.0 \%$ vs $72.2 \%, P=0.003)$ [13]. We do not recommend the routine use of a stylet during EUS-FNA because it prolongs the procedure, increases the amount of blood in the specimen, and does not improve the accuracy of the diagnosis. Finally, when sampling pancreatic masses, one reaches a point of "diminishing returns" after seven passes [14]. The most common reason for non-diagnostic interpretation is inadequate sampling and, hence, a sufficient number of passes must be performed to yield an adequate sample.

Therefore, our recommendations to endosonographers for superior outcomes during EUS-FNA of the pancreas include: 1) use of a $25 \mathrm{G}$ needle, 2) use of a 19/22G needle if the diagnosis is to be established only by cell block or when ROSE is not available, 3) use of the fanning technique, 4) avoidance of the routine use of suction and stylet, 5) procuring an adequate quantity of the specimen, 6) learning to self-assess for diagnostic adequacy of FNA specimens if ROSE is not available, and 7) hiring the services of an expert cytopathologist who can provide off-site interpretations. EUS-FNA is an art - just keep it simple!

\section{Abbreviations \\ $\nabla$ \\ EUS endoscopic ultrasound \\ FNA fine needle aspiration \\ ROSE rapid on-site evaluation}

\section{Competing interests: None}

\section{References}

1 Tempero MA, Arnoletti JP, Behrman S et al. Pancreatic adenocarcinoma. J Natl Compr Canc Netw 2010; 8: 972 - 1017

2 Hébert-Magee S, Bae S, Varadarajulu $S$ et al. The presence of a cytopathologist increases the diagnostic accuracy of endoscopic ultrasoundguided fine needle aspiration cytology for pancreatic adenocarcinoma: a meta-analysis. Cytopathology 2013; 24: 159-171

3 Al-Abbadi MA, Bloom LI, Fatheree LA et al. Adequate reimbursement is crucial to support cost-effective rapid on-site cytopathology evaluations. Cytojournal 2010; 7: 22

4 Schneider A, Nerlich A, Topalidis $T$ et al. Specialized clinical cytology may improve the results of EUS-guided fine needle aspiration from pancreatic tumors. EIO Efirst

5 Eltoum IA, Chhieng DC, Jhala D et al. Cumulative sum procedure in evaluation of EUS-guided FNA cytology: the learning curve and diagnostic performance beyond sensitivity and specificity. Cytopathoplogy 2007; 18: $143-150$

6 Eloubeidi MA, Tamhane A. EUS-guided FNA of solid pancreatic masses: a learning curve with 300 consecutive procedures. Gastrointest Endosc 2005; 61: $700-708$

7 Hikichi T, Irisawa A, Bhutani MS et al. Endoscopic ultrasound-guided fine-needle aspiration of solid pancreatic masses with rapid on-site cytological evaluation by endosonographers without attendance of cytopathologists. J Gastroenterol 2009; 44: $322-328$

8 Varadarajulu S, Holt BA, BangJY et al. Training endosonographers in cytopathology: improving the results of EUS-guided FNA. Gastrointest Endosc 12. 08 2014: [Epub ahead of print]

9 Madhoun MF, Wani SB, Rastogi A et al. The diagnostic accuracy of 22 gauge and 25-gauge needles in endoscopic ultrasound-guided fine needle aspiration of solid pancreatic lesions: A meta-analysis. Endoscopy 2013; 45: 86-92

10 Varadarajulu S, Bang JY, Holt BA et al. The 25-gauge EUS-FNA needle: Good for on-site but poor for off-site evaluation? Results of a randomized trial Gastrointest Endosc 25. 06 2014: [Epub ahead of print]

11 Bang JY, Hawes RH, Hasan MK et al. EUS-Guided Tissue Acquisition: Meta-Analysis Comparing the Procore and Standard FNA Needles. Gastrointest Endosc 2014; 79: AB427

12 Bang JY, Hébert-Magee S, Ramesh J et al. Randomized trial comparing fanning with standard technique for endoscopic ultrasound-guided fine-needle aspiration of solid pancreatic mass lesions. Endoscopy 2013; 45: $445-450$

13 Kudo T, Kawakami H, Hayashi T et al. High and low negative pressure suction techniques in EUS-guided fine-needle tissue acquisition by using 25-gauge needles: a multicenter, prospective, randomized, controlled trial. Gastrointest Endosc 2014; 80: 1030-1037

14 Jhala NC, Jhala D, Eltoum I et al. Endoscopic ultrasound-guided fineneedle aspiration biopsy: a powerful tool to obtain samples from small lesions. Cancer 2004; 102: 239-246 